\title{
Antimicrobial, Thrombolytic, Membrane Stabilizing Activities and Total Flavonoid Content of Various Partitionates of Aerial Parts of Eclipta alba (L.) Hassk
}

\section{J alal Uddin ${ }^{1}$, Azima Sultana J ulie ${ }^{1}$, Md Haider Ali $^{1}$, Md. Nurul Islam², Shah Alam Khan ${ }^{3}$ and Zubair Khalid Labu ${ }^{1}$}

\author{
${ }^{1}$ Department of Pharmacy, World University of Bangladesh, 151/8, Green Road, Dhaka-1205, Bangladesh \\ ${ }^{2}$ Amico Laboratories Ltd., Dhaka, Bangladesh \\ ${ }^{3}$ Department of Pharmacy, Oman Medical College, Muscat, Sultanate of Oman
}

Received: August 16, 2015; Accepted: November 29, 2015; Published (web): January 31, 2016

\begin{abstract}
Eclipta alba is a medicinal herb belonging to the family of Asteraceae. Locally it is known as Kalokeshi and has a history of ethno-medicinal properties. The crude ethanolic extract of E. alba leaves was partitioned successively by solvents of different polarities. The crude extract along with different partitionates was evaluated for their possible antimicrobial, thrombolytic and membrane stabilizing activities. In this study, $n$-hexane soluble fraction (HXSF) showed 55.56\% maximum activity against thrombosis in comparison with streptokinase (SK) $62.67 \%$. For hypotonic solution- and heat-induced conditions, the $n$-hexane soluble fractionate $(67.35 \pm 0.50 \%)$ significantly inhibited the haemolysis of HRBCs by $67.35 \pm 0.50 \%$ and $62.12 \pm 0.69 \%$, respectively as compared to the standard acetyl salicylic acid $(77.91 \pm 0.29 \%)$. The ethanol extract of the plant showed higher inhibitory action against Staphylococcus aureus, Bacillus subtilis, Proteus mirabilis and Pseudomonas fluroescens. The total flavonoid content was quite significant in ethanolic extract $(142.17 \pm 0.15 \mathrm{mg} / \mathrm{g})$. Hence, the results of the present study revealed that the leaves of this traditional medicinal plant are a remedy for thrombosis, red blood cell membrane stabilization and microbial infections against some human pathogens.
\end{abstract}

Key words: Eclipta alba, phytochemical screening, thrombolytic activity, membrane stabilizing activity, antimicrobial activity

\section{INTRODUCTION}

In the modern medicinal system, people have started looking at the ancient healing systems like Ayurveda, Siddha and Unnani due to the high adverse effects associated with synthetic drugs. ${ }^{1}$ Herbal drugs play an important role in health care programs especially in developing countries. Ancient Indian literatures incorporate a remarkably broad definition of medicinal plants and consider all plant parts to be potential sources of medicinal substances. ${ }^{2}$

Correspondence to: Zubair Khalid Labu

Tel: +88-01558388956;

E-mail: zubair.labu@yahoo.com

Dhaka Univ. J. Pharm. Sci. 14(2): 207-213, 2015 (December)
Eclipta alba (family: Asteraceae) occurs worldwide in the tropics and subtropics. It is distributed throughout East Asia (China, Japan and Korea), South and Southeast Asia (Bangladesh, India Indonesia, Cambodia, Malaysia, Nepal, Pakistan, Philippines, Sri Lanka, Thailand and Vietnam) and in some other parts of the world. It is widely used as a folkloric medicine in Bangladesh. The local name of E. alba is Kalokeshi. It has been reported that aerial parts of this plant contain various phytochemicals such as $\beta$-amyrin, luteolin-7-O-glucoside, phytosterol, apigenin, cinnaroside sulphur compounds eclabasaponins I-VI, stigmasterol, $\alpha$-terthienymethanol, wedelolactone (1.6\%), demethylwedelolactone, demethyl-wedelolactone-7-glucoside. Hentriacontanol, heptacosanol, stigmasterol, ecliptal, thiophene acetylenes has already been detected in the 
roots of this plant. $^{3}$ Whole plant is used as rejuvenating, antiseptic herb in vitiated blood, anemia, splenic and liver enlargements, catarrhal jaundice, hyperacidity, gastritis, dysentery, anticatarrhal and spasmogenic. Juice of leaves is useful in skin diseases, allergic urticaria, asthma, in flatulence, colic and liver affections, bronchitis, enlarged glands, dizziness, vertigo and blurred vision. ${ }^{4} \mathrm{~A}$ decoction of the plant is given to liver disease, gray hair, stomach bleedings, spermatorrhoea and menorrhagia. ${ }^{5}$ A paste of it is used in headache and toothache. Root of this plant is widely used as liver tonic, emetic, purgative, antiseptic to ulcers and wounds in cattle. ${ }^{6}$ There is no known drug interaction with Eclipta but always, make sure to consult with a qualified health care practitioner before taking Eclipta or any other herbal product or dietary supplement. ${ }^{7}$ The American herbal products association has stated that Eclipta can be safely consumed but should not be taken by patients who have acute or chronic diarrhea, or patients who have deficient cold in the spleen. ${ }^{8}$ Finally, the research activities have been focused on the phytochemical investigation of the plants which have ethno-botanical and folkloric importance associated with them for drug discovery. ${ }^{9}, 10$ Because of its widespread availability and folkloric uses, the present study was undertaken to investigate $E$. alba leaves extract for membrane stabilizing, thrombolytic and antimicrobial activities.

\section{MATERIALS AND METHODS}

Plant materials. The plant, Eclipta alba was collected from the National Botanical Garden, Dhaka, Bangladesh in May, 2014 and was identified by the taxonomist of Bangladesh National Herbarium, Mirpur, Dhaka. A voucher specimen for this plant has been maintained in Bangladesh National Herbarium for future reference.

Preparation of extract. The collected plant leaves were shade dried for several days and then oven dried for 24 hours at $40{ }^{\circ} \mathrm{C}$ to facilitate grinding. The powdered leaves were then stored in a tight container. The dried powder material (400 g) was soaked in $1000 \mathrm{ml}$ of $90 \%$ ethanol for two weeks and was shaken occasionally. The whole mixture was filtered by a piece of clean, white cotton followed by Whatman filter paper. The filtrate was dried using a vacuum rotary evaporator at optimum temperature at $50{ }^{\circ} \mathrm{C}$ to obtain the crude extract of E. alba. The concentrated aqueous ethanol extract was partitioned by the Kupchan method and the resultant partitionates i.e. hexane, chloroform, ethyl acetate and aqueous soluble materials were used for the current investigation.

Phytochemical screening. The freshly prepared organic extracts were qualitatively tested for the presence of various classes of phytochemicals, as described by Sofowara. ${ }^{11}$

Determination of total flavonoid content. The total flavonoid content was estimated using a method previously described by Kumaran and Karunakaran using quercetin as a reference compound. ${ }^{12}$

To determine total flavonoid of this study, $1 \mathrm{ml}$ of leaves extract in methanol $(250 \mu \mathrm{g} / \mathrm{ml})$ was mixed with $1 \mathrm{ml}$ aluminum chloride in ethanol $(20 \mathrm{mg} / \mathrm{ml})$ and a drop of acetic acid, and then diluted with ethanol to $25 \mathrm{ml}$. The absorption at $415 \mathrm{~nm}$ was read after 40 min. A blank sample was prepared in similar way without the extracts. The absorption of standard quercetin solution $(0.5 \mathrm{mg} / \mathrm{ml})$ in ethanol was measured under the same conditions.

\section{In vitro thrombolytic activity}

Sample preparation. The crude extract was mixed with $10 \mathrm{ml}$ of sterile distilled water and shaken vigorously on a sonicator. The suspension was kept overnight and decanted to remove soluble supernatant, which was filtered through a filter paper. The solution was then ready for in vitro evaluation of clot lysis activity.

Thrombolytic assay. The thrombolytic activity of prepared extracts was evaluated by the method of Daginawala, using streptokinase (SK) as a standard drug. ${ }^{13}$ Venous blood $(5 \mathrm{ml})$ was drawn from healthy volunteers, and transferred in different pre-weighed sterile tubes $(1 \mathrm{ml} /$ tube) to form clots and incubated at $37{ }^{\circ} \mathrm{C}$ for 45 minutes. After clot formation, the 
serum was completely removed without disturbing the clot formed and each tube having clot, was again weighed to determine the clot weight [clot weight $=$ weight of clot containing tube - weight of tube alone]. The tubes containing pre-weighed clot was properly labeled and $100 \mu \mathrm{l}$ crude extract as well as aqueous solution of different fractionates were added to the tubes separately. As a positive control, $100 \mu \mathrm{l}$ of SK and $100 \mu \mathrm{l}$ of isotonic (a negative non thrombolytic control) solution were separately added to two clot containing tubes. All the tubes were then incubated at $37{ }^{\circ} \mathrm{C}$ for 90 minutes and observed for clot lysis. After incubation, the released fluid was removed and vials were again weighed to observe the difference in weight after clot disruption. Differences obtained in weight taken before and after clot lysis was expressed as percentage of clot lysis as shown below:

$\%$ of clot lysis $=($ wt. of released clot /clot wt. $) \times 100$

The significance between percentages of clot lysis of crude extract by means of weight difference was tested by the paired t-test analysis. Statistical analysis was performed with the results of percentage of clot lysis by different fractionates, streptokinase and sterile water, where $\mathrm{p}$ values $<0.01$ was considered statistically significant (Table 3 ).

In vitro membrane stabilizing activity. The membrane stabilizing activity of the extractives was determined on human erythrocytes by the method of Omale. $^{14}$

\section{Hypotonic-solution induced hemolysis.} The experiment was carried out with hypotonic solution. The test sample contained stock erythrocyte (RBC) suspension $(0.5 \mathrm{ml})$ with $5 \mathrm{ml}$ hypotonic solution, different fractions of ethanolic extract $(2 \mathrm{mg} / \mathrm{ml})$ and acetyl salicylic acid $(0.1 \mathrm{mg} / \mathrm{ml})$. The mixtures were centrifuged for $10 \mathrm{~min}$ at $3000 \mathrm{rpm}$, and incubated for $10 \mathrm{~min}$ at a room temperature of $25{ }^{\circ} \mathrm{C}$. The absorbance of supernatant content haemoglobin was measured at $540 \mathrm{~nm}$ using UV spectrophotometer. The percentage inhibition of either haemolysis or membrane stabilization was calculated using the following equation:

$\%$ inhibition of haemolysis $=100 \times\left\{\left(\mathrm{OD}_{1}-\mathrm{OD}_{2}\right) / \mathrm{OD}_{1}\right\}$ where, $\mathrm{OD}_{1}=$ Optical density of hypotonic buffered saline solution alone (control) and $\mathrm{OD}_{2}=$ optical density of the test sample in hypotonic solution.

Heat-induced haemolysis. Isotonic buffer solution containing $2 \mathrm{mg} / \mathrm{ml}$ of different fractions of E. alba were put into two centrifuge tubes. ${ }^{15}$ Two sets of control tubes containing $5 \mathrm{ml}$ of sterile vehicle and $5 \mathrm{ml}$ of acetyl salicylic acid $(0.1 \mathrm{mg} / \mathrm{ml})$ were maintained. Erythrocyte suspension (30 ul) was added to each tube and mixed gently by inversion. A pair of tubes was incubated at $54{ }^{\circ} \mathrm{C}$ for $20 \mathrm{~min}$ in a water bath. The other pair was maintained at $0-5{ }^{\circ} \mathrm{C}$ in an ice bath. The reaction mixture was centrifuged for $10 \mathrm{~min}$ at $3000 \mathrm{rpm}$ and the absorbance of the haemoglobin content in supernatant was measured at $540 \mathrm{~nm}$.

The percentage inhibition or acceleration of haemolysis was calculated according to the following equation:

$\%$ inhibition of haemolysis

$=\frac{O D_{3}-O D_{2}}{O D_{3}-O D_{1}} \times 100$

where, $\mathrm{OD}_{1}=$ absorbance of test sample unheated, $\mathrm{OD}_{2}=$ absorbance of test sample heated and $\mathrm{OD}_{3}=$ absorbance of test control sample.

Test bacteria. A total of eight bacterial species used were obtained from the Department of Microbiology, University of Dhaka (Table 6). The bacterial strains were maintained on nutrient agar slants at $4{ }^{\circ} \mathrm{C}$.

Antibacterial activity. The extracts obtained were screened for their antibacterial activity in comparison with standard antibiotic doxycycline (10 $\mu \mathrm{g} / \mathrm{disc}$ ) in vitro by disc diffusion method using various bacterial strains. ${ }^{16,17}$ The zone of inhibition around each disc was measured in millimeter and the assay was carried out three times for each extract.

\section{RESULTS AND DISCUSSION}

Phytochemical screening was performed on the crude ethanolic extract of $E$. alba and its partitionates 
using standard procedures to identify the active constituents. It revealed the presence of saponins, alkaloids, flavonoid and tannins in all the extractives while reducing sugar was not detected (Table 1).

Table 1. Results of phytochemical screening of different partitionates of E. alba.

\begin{tabular}{lclll}
\hline Test for & EE & HXSF & CSF & ESF \\
\hline Carbohydrates & + & - & + & + \\
Steroid & + & + & - & - \\
Reducing sugar & - & - & + & + \\
Alkaloids & + & + & + & + \\
Tannins & - & + & + & + \\
Flavonoids & + & + & & \\
\hline + Indicates present; & - indicates absent & &
\end{tabular}

Total flavonoid content. Total flavonoid contents of various fractions of $E$. alba leaves extracts were expressed as $\mathrm{mg}$ of quercetin equivalents/gm of dried extract (Table 2).

Table 2. Total flavonoids contents of the ethanolic extracts of E. alba.

\begin{tabular}{cc}
\hline $\begin{array}{c}\text { Different fractionates of leave } \\
\text { extract }\end{array}$ & $\begin{array}{c}\text { Total flavonoids mg/g plant } \\
\text { extract (in QAE) }\end{array}$ \\
\hline ESF & $142.17 \pm 0.15$ \\
HXSF & $49.47 \pm 0.47$ \\
CSF & $60.76 \pm 1.80$ \\
\hline
\end{tabular}

Results are expressed as mean \pm SD

Although all the fractions exhibited positive results while hexane soluble fraction was found to contain the lowest flavonoid $(49.47 \pm 0.47 \mathrm{mg} / \mathrm{g})$. The total flavonoid contents of leaves of E. alba was calculated using the standard curve of quercetin $(\mathrm{y}=0.0098 \mathrm{x}$ $0.0364 ; \mathrm{R}^{2}=0.9724$ ).

Thrombolytic activity. The in vitro thrombolytic activity study revealed that the addition of $100 \mu \mathrm{l}$ streptokinase (SK, 30,000IU) to the clots and subsequent incubation for 90 minutes at $37{ }^{\circ} \mathrm{C}$ showed $62.67 \%$ lysis of clot. On the other hand, sterile distilled water, a negative control, exhibited a negligible percentage of lysis of clot (3.23\%). The percentage of clot lysis with ethanol soluble fraction (ESF), hexane soluble fraction (HXSF), chloroform soluble fraction (CSF) and aqueous soluble fraction (AQSF) were $37.33 \%, 55.56 \%, 36.11 \%$ and $10.87 \%$ respectively. In this study, it was observed that the hexane soluble fraction of $E$. alba showed highest thrombolytic activity as presented in table 3 .

Table 3. Thrombolytic activity of different fractionates crude extract of E. alba.

\begin{tabular}{lcccccc}
\hline Fractions & $\begin{array}{c}\text { Weight of } \\
\text { empty vial } \\
\text { (A) g }\end{array}$ & $\begin{array}{c}\text { Weight of vial } \\
\text { with clot (B) g }\end{array}$ & $\begin{array}{c}\text { Weight of clot } \\
\text { (B-A) g }\end{array}$ & $\begin{array}{c}\text { Weight of vial } \\
\text { with clot after } \\
\text { lysis (D) g }\end{array}$ & $\begin{array}{c}\text { Weight of clot lysis } \\
\text { (B-D) g }\end{array}$ & $\begin{array}{c}\text { \%of clot } \\
\text { lysis }\end{array}$ \\
\hline ESF & 5.29 & 6.04 & 0.75 & 5.76 & 0.28 & $37.33^{*}$ \\
HXSF & 5.31 & 6.30 & 0.99 & 5.75 & 0.55 & $55.56^{*}$ \\
CSF & 5.42 & 6.14 & 0.72 & 5.88 & 0.26 & $36.11^{*}$ \\
Blank & 5.21 & 5.51 & 0.31 & 5.52 & 0.01 & $3.23^{*}$ \\
SK & 5.12 & 5.87 & 0.75 & 5.40 & 0.47 & $62.67^{*}$ \\
AQSF & 4.90 & 5.82 & 0.92 & 5.72 & 0.1 & $10.87^{*}$ \\
\hline
\end{tabular}

$* \mathrm{P}<0.01$, crude extracts are significant as compared to positive control and negative control

Membrane stabilizing activity. In vitro membrane stabilizing activity revealed that, at 2 $\mathrm{mg} / \mathrm{ml}$, different partitionates of crude extracts of $E$. alba significantly protected the haemolysis of HRBC membrane induced by hypnotic solution and heat as compared to the standard ASA (Table 4). 
Table 4. Percentage (\%) inhibition of heat and hypotonic solution induced haemolysis of erythrocyte membrane by standard and different fractions of $E$. alba.

\begin{tabular}{lcc}
\hline Samples & \multicolumn{2}{c}{ \% Inhibition of haemolysis } \\
\hline & Heat-induced & $\begin{array}{c}\text { Hypotonic } \\
\text { solution-induced }\end{array}$ \\
\hline ESF & $46.53 \pm 0.61$ & $55.23 \pm 0.64$ \\
HXSF & $60.12 \pm 0.64$ & $67.35 \pm 0.50$ \\
CSF & $44.22 \pm 0.57$ & $48.61 \pm 0.77$ \\
AQSF & $21.34 \pm 0.42$ & $28.48 \pm 0.51$ \\
ASA & $70.12 \pm 0.26$ & $77.91 \pm 0.29$ \\
\hline
\end{tabular}

Values are expressed as mean $\pm \mathrm{SD}$ (standard deviation); $\mathrm{ESF}=$ ethyl soluble fraction, $\mathrm{HXSF}=$ hexane soluble fraction, $\mathrm{CSF}=$ chloroform soluble fraction, $\mathrm{AQSE}=$ aqueous soluble fraction, ASA = acetyl acetic acid.

The results of this study showed that, hexane soluble fraction of E. alba showed $67.35 \pm 0.50 \%$ and $60.12 \pm 0.69 \%$ inhibition of haemolysis induced by hypnotic solution and heat, respectively and thus protected the haemolysis of HRBC membrane. So, it can be proposed that the inhibition of erythrocyte lysis property of $E$. alba could be the possible mechanism for its anti-inflammatory activity.

Antibacterial activity. The antibacterial activity of the ethanolic extract of leaf of $E$. alba was studied against both gram positive microbes and gram negative species at 4 different concentrations (1000, 2000, 5000 and $10000 \mu \mathrm{g} / \mathrm{ml})$. The antibacterial activity was compared with the standard doxycycline $(10 \mu \mathrm{g} / \mathrm{disc})$. The results of antibacterial screening are presented in tables 5 and 6 , which revealed the variability in inhibitory concentrations of each extract against a given bacteria. The inhibition of bacterial growth was dose dependent since the inhibitory action of the extract was found to increase with an increase in concentration against all bacteria strains as evidenced by the higher zone of inhibitions at higher concentrations of each extract. Among the various extracts used, hexane extracts of $E$. alba showed the highest activity (zone of inhibition 18.4 $\mathrm{mm}$ ) against $P$. mirabilis. Hexne extract was appeared to be most effective extract. None of the water extracts showed any antibacterial activity. None of the chloroform extracts was active against any of the gram positive bacteria tested. The antibacterial activity was more prominent on the gram negative bacteria than the gram positive bacteria. The mean zone of inhibition for the positive control was penicillin.

Table 5. Antibacterial activity of extracts of $E$. alba against Gram positive bacteria.

\begin{tabular}{|c|c|c|c|c|c|}
\hline \multirow[b]{2}{*}{ Extract } & \multirow{2}{*}{$\begin{array}{c}\text { Concentration of } \\
\text { extract } \\
(\mathrm{mg} / \mathrm{ml})\end{array}$} & \multicolumn{4}{|c|}{ Zone of inhibition $(\mathrm{mm})$ Gram positive bacteria } \\
\hline & & S. aureus & B. subtilis & B. cereus & Doxycycline \\
\hline \multirow{4}{*}{ Ethyl acetate } & 1 & $9.4 \pm 0.04$ & _ & _- & $17 \pm 0.21$ \\
\hline & 2 & $11.2 \pm 0.16$ & - & - & $23 \pm 0.17$ \\
\hline & 5 & $12.5 \pm 0.12$ & $11.4 \pm 0.15$ & - & $29 \pm 0.13$ \\
\hline & 10 & $14.5 \pm 0.16$ & $12.8 \pm 0.28$ & - & $44 \pm 0.16$ \\
\hline \multirow{5}{*}{ Chloroform } & 1 & _- & - & - & $14 \pm 0.11$ \\
\hline & 2 & - & - & - & $22 \pm 0.10$ \\
\hline & 5 & - & - & - & $31 \pm 0.10$ \\
\hline & 10 & _- & - & _- & $43 \pm 0.11$ \\
\hline & 1 & $9.5 \pm 0.36$ & _- & _ & $16 \pm 0.12$ \\
\hline \multirow{3}{*}{ Ethanol } & 2 & $10.7 \pm 0.38$ & - & - & $26 \pm 0.19$ \\
\hline & 5 & $12.8 \pm 0.02$ & $11.7 \pm 0.25$ & $8.5 \pm 0.48$ & $35 \pm 0.10$ \\
\hline & 10 & $17.3 \pm 0.18$ & $12.5 \pm 0.22$ & $9.8 \pm 0.33$ & $47 \pm 0.19$ \\
\hline \multirow{5}{*}{ Aqueous } & 1 & _ & - & - & - \\
\hline & 2 & - & - & - & - \\
\hline & 5 & _- & _- & _- & _- \\
\hline & 10 & _- & - & - & _ \\
\hline & 1 & - & $7.4 \pm 0.043$ & - & $19 \pm 0.17$ \\
\hline \multirow{3}{*}{$n$-hexane } & 2 & - & $10.2 \pm 0.39$ & - & $29 \pm 0.19$ \\
\hline & 5 & $7.8 \pm 0.03$ & $13.3 \pm 0.67$ & $7.5 \pm 0.48$ & $38 \pm 0.16$ \\
\hline & 10 & $9.7 \pm 0.02$ & $16.9 \pm 0.26$ & $9.7 \pm 0.33$ & $51 \pm 0.17$ \\
\hline
\end{tabular}


Table 6. Antibacterial activity of extracts of $E$. alba against Gram negative bacteria.

\begin{tabular}{|c|c|c|c|c|c|c|c|}
\hline \multirow{2}{*}{ Extract } & \multirow{2}{*}{$\begin{array}{l}\text { Conc.of extract } \\
(\mathrm{mg} / \mathrm{ml})\end{array}$} & \multicolumn{6}{|c|}{ Zone of inhibition $(\mathrm{mm})$ Gram negative bacteria } \\
\hline & & E. coli & P. mirabilis & P. fluroescens & P. aeruginosa & S. typhi & Doxycycline \\
\hline \multirow{4}{*}{ Ethyl acetate } & 1 & $8.2 \pm 0.54$ & _- & _- & - & - & $10 \pm 0.21$ \\
\hline & 2 & $10.2 \pm 0.43$ & - & _- & _- & - & $23 \pm 0.17$ \\
\hline & 5 & $12.0 \pm 0.79$ & $13.2 \pm 0.35$ & $9.4 \pm 0.59$ & $8.1 \pm 0.33$ & $7.9 \pm 0.84$ & $29 \pm 0.13$ \\
\hline & 10 & $16.2 \pm 0.24$ & $14.6 \pm 0.34$ & $13.3 \pm 0.36$ & $11.9 \pm 0.24$ & $7.2 \pm 0.64$ & $37 \pm 0.16$ \\
\hline \multirow{5}{*}{ Chloroform } & 1 & _ & _ & $7.9 \pm 0.17$ & _ & _ & $11 \pm 0.21$ \\
\hline & 2 & _ & _ & $9.3 \pm 0.38$ & _ & _ & $20 \pm 0.17$ \\
\hline & 5 & $9.3 \pm 0.18$ & _- & $11.7 \pm 0.36$ & $8.1 \pm 0.33$ & _- & $28 \pm 0.13$ \\
\hline & 10 & $12.3 \pm 0.57$ & _ & $14.9 \pm 0.29$ & $11.8 \pm 0.24$ & $8.2 \pm 0.64$ & $37 \pm 0.16$ \\
\hline & 1 & $7.3 \pm 0.49$ & $8.4 \pm 0.22$ & $7.3 \pm 0.24$ & $7.2 \pm 0.32$ & _ & $12 \pm 0.21$ \\
\hline \multirow{3}{*}{ Ethanol } & 2 & $9.4 \pm 0.18$ & $10.5 \pm 0.55$ & $9.4 \pm 0.44$ & $8.2 \pm 0.52$ & _ & $17 \pm 0.17$ \\
\hline & 5 & $12.3 \pm 0.31$ & $13.2 \pm 0.75$ & $11.6 \pm 0.66$ & $9.6 \pm 0.22$ & $7.2 \pm 0.26$ & $24 \pm 0.13$ \\
\hline & 10 & $14.0 \pm 0.22$ & $16.2 \pm 0.82$ & $14.5 \pm 0.29$ & $10.6 \pm 0.12$ & $7.8 \pm 0.14$ & $33 \pm 0.16$ \\
\hline \multirow{5}{*}{ Aqueous } & 1 & - & - & - & - & - & - \\
\hline & 2 & - & - & - & - & - & - \\
\hline & 5 & - & - & - & - & - & - \\
\hline & 10 & - & - & - & - & - & - \\
\hline & 1 & $3 \pm 11.09$ & $9.3 \pm 0.12$ & $7.1 \pm 0.68$ & $10.4 \pm 0.49$ & $5.6 \pm 0.75$ & $11 \pm 0.29$ \\
\hline \multirow{3}{*}{$n$-hexane } & 2 & $6 \pm 11.09$ & $11.3 \pm 0.32$ & $8.6 \pm 0.17$ & $13.3 \pm 0.39$ & $7.9 \pm 0.38$ & $19 \pm 0.17$ \\
\hline & 5 & $8.2 \pm 0.66$ & $15.3 \pm 0.33$ & $11.3 \pm 0.19$ & $14.8 \pm 0.58$ & $8.4 \pm 0.52$ & $29 \pm 0.13$ \\
\hline & 10 & $12.1 \pm 0.78$ & $18.4 \pm 0.35$ & $15.5 \pm 0.33$ & $17.9 \pm 0.73$ & $11.8 \pm 0.69$ & $38 \pm 0.16$ \\
\hline
\end{tabular}

The results are mean $\pm \mathrm{SD}(\mathrm{n}=3)$

Medicinal plants are important source for the development of potential new chemotherapeutic drugs. The broad spectrum antibacterial activities of the plant extract, possibly due to the identified alkaloids, further confirm its use as a remedy in folkloric medicine. ${ }^{18}$ Plant extracts often contain polyphenols and flavonoids which could be the antimicrobial components. The bioactivity of plants extracts is attributed to phytochemical constituents. Flavonoids are a major group of phenolic compounds reported for their antiviral, antimicrobial and spasmolytic properties. Alkaloids isolated from plants are commonly found to have antimicrobial properties. The antibacterial activities of these compounds might be due to their ability to complex with bacterial cell wall and therefore, inhibiting the microbial growth. ${ }^{19}$

\section{CONCLUSION}

The extractives of $E$. alba showed significant in vitro thrombolytic and membrane stabilizing but moderate antimicrobial activities. It may be assumed that these extracts can be considered as good source of antimicrobial, thrombolytic and membrane stabilizing agents. Many anti-inflammatory plants and agents modify inflammatory responses by accelerating the destruction or antagonizing the action of the mediators of inflammatory reaction. These reports, suggest that the flavonoids in extract of E. alba might be a major anti-inflammatory constituent. However, more detailed phytochemical analysis will be necessary to isolate and characterize the active compounds responsible for the thrombolytic and membrane stabilizing activities as well as to understand the exact mechanisms of action of these activities. The present study also justifies the claimed uses of E. alba in the traditional system of medicine to treat various infectious diseases caused by the microbes.

\section{REFERENCES}

1. Bigoniya, P. Singh, C.S. and Shukla, A. 2011. Pharmacol and physicochemical standardization of ethno Pharmacol. Important seeds of Lepidium sativum Linn. Indian J. Nat. Prod. Res. 2, pp. 464-471.

2. Shankar, D. and Ved, D.K. 2003. Pharmacognosy evaluation and physicochemical analysis of E. alba. Indian Forester. 129, 275-288

3. Chopra, R.N., Nayar, S.L. and Chopra, I.C. 1956. Glossary of Indian Medicinal plants. C. S. I. R. New Delhi. 3, pp. 232238. 
4. Jadhav, V.M., Thorat, R.M. and Kadam, V.J. 2009. Eclipta alba Linn-Kesharaja. J. Pharm. Res. 2, pp.1236-1241

5. Neeraja, P.V. and Elizabeth, M. 2012. Eclipta alba (L.) Hassk: A Valuable Medicinal herb. Int. J. Current Pharma. Review Res. 2, pp.188-197

6. Khare, C.P. 2004. Indian herbal remedies: Rational western therapy, Ayurvedic and other traditional usage, Botany. Berlin: Springer, pp. 451-452.

7. Manjit, I.S.S., Ravneet, K. and Raghbir, C.G. 2010. Comparison of antibacterial activity of three morphotypes of medicinal herb E. alba (L.). Hassk. Der Pharmacia Lett. 2 , 200-207

8. Murray, P.R. and Baron, E.J. 2003. Manual of clinical microbiology. American Soc. Microbiol. 1, 258-260.

9. Rastogi, R.P. and Mehrotra, B.N. 1993. Compendium of Indian Medicinal Plants. Central Drug Research Institute, Lucknow and Publications \& Information Directorate, New Delhi, India. 2, p.10.

10. Panda, B.K., Patra, V.J. and Mishra, U.S.S. 2009. Analgesic activities of the stem bark extract of Spondias pinata (Linn. f) Kurz. J. Pharm. Res. 2, 825-827.

11. Sofowara, A. 1993. Medicinal plants and traditional medicine in Africa. Spectrum Books Ltd., Ibadan, Nigeria. p. 289

12. Kumaran, A. and Karunakaran, R.J. 2007. In vitro antioxidant activities of methanol extracts of five Phyllanthus species from India. L.W.T-Food Sci Technol. 40, pp. 344352.

13. Daginawala, H.F., Prasad, S., Kashyap, R.S., Deopujari, J.W., Purothi, H.J. and Taori, G.M. 2006. Development of an in vitro model to study clot lysis activity of thrombolytic drugs. Thrombosis J. 4, 14.

14. Omale, J. and Okafor, P.N. 2008. Comparative antioxidant capacity, membrane stabilization, polyphenol composition and cytotoxicity of the leaf and stem of Cissus multistriata. Afr. J. Biotechnol. 7, 3129-3133.

15. Shinde, U.A., Phadke, A.S. and Nair, A.M. 1989. Membrane stabilization activity- a possible mechanism of action for the anti-inflammatory activity of Cedrus deodara wood oil. Fitoterapia 70, 251-257.

16. Bauer, A.W., Kirby, W.M.M. and Sherris, J.C. 1966. In vitro antibacterial activity of Eclipta alba. Am. J. Clin. Pathol. 45, 493-496.

17. Sainath, R.S., Prathiba, J. and Malathi, R. 2009. In vitro antibacterial activity of Eclipta alba. Eur. Rev. Med. Pharmacol. Sci. 13, 371-374.

18. Doughari, J.H., El-mahmood, A.M. and Jyoyina, I. 2008. In vitro antibacterial activity of E. alba (L.) Hassk. Afr. J. Pharm. Pharmacol. 2, 7-13

19. Mehrangiz, K.K., Seyed, A.E., Masoud, S.G., Esmaeel, A.S. and Amirhossein, S. 2011. In vitro antibacterial activity of Eclipta alba (L.) Hassk. Asian Biomed. 5, 63-68. 